\title{
A inserção do brincar e brinquedo nas práticas de enfermagem pediátrica: pesquisa convergente assistencial
}

\author{
The insertion of play and toys in Pediatric Nursing practices: A convergent care research \\ La inserción del juego y los juguetes en las prácticas de enfermería pediátrica: investigación \\ convergente asistencial
}

\begin{abstract}
Maria Izabel Sartori Claus ${ }^{1}$ (B)
Edmara Bazoni Soares Maia² (1)

Ana Izaura Basso de Oliveira ${ }^{3}$ (1)

Aline Landim Ramos ${ }^{3}$ (D)

Patrícia Luciana Moreira Dias ${ }^{3}$ (1)
\end{abstract}

Monika Wernet ${ }^{3}$ (1)

1. Universidade de São Paulo, Programa de Residência em Enfermagem em Saúde da Criança e do Adolescente. São Paulo, SP, Brasil.

2. Universidade Federal de São Paulo, Departamento de Enfermagem Pediátrica, Escola Paulista de Enfermagem. São Paulo, SP, Brasil.

3. Universidade Federal de São Carlos. São Carlos, SP, Brasil.
Autor correspondente:

Edmara Bazoni Soares Maia.

Email: maiaedmara@gmail.com.

Recebido em 14/09/2020.

Aprovado em 21/12/2020.

DOI:https://doi.org/10.1590/2177-9465-EAN-2020-0383

\section{Resumo}

Objetivo: analisar o processo de apreensão e transformação do uso do brincar e brinquedo pela equipe de enfermagem de uma unidade pediátrica. Método: estudo apoiado na pesquisa convergente assistencial, envolvendo rodas de conversas com 11 profissionais de uma equipe de enfermagem, atuantes em uma unidade de internação pediátrica de um hospital de ensino. Foi desenvolvido entre Dezembro de 2018 e Maio de 2019. Resultados: Houve reconhecimento do brincar como inerente à criança e benéfico na interação com esta, quando hospitalizada. Os participantes percebem a não apropriação do brincar estruturado em suas práticas, prospectam ampliação, porém identificam entraves associados ao pouco apoio institucional Dos desdobramentos, decidiram por inserção do fantoche e capacitação para o uso do brincar estruturado. Conclusões e implicações para a prática: a inserção do brincar no hospital demanda ruptura com o modelo biomédico em saúde e apostas em uma cultura institucional de reconhecimento do brincar. O brincar ao longo da hospitalização integra um cuidado justo, humano e integral, que deve ser para a equipe de enfermagem motivo de luta e garantia, correspondendo às instituições, o dever de dar suporte, tanto no âmbito dos processos de trabalho, quanto no da educação permanente.

Palavras-chave: Criança Hospitalizada; Enfermagem Pediátrica; Jogos e Brinquedo; Competência Profissional; Educação Continuada.

\section{Abstract}

Objective: to analyze the process of apprehension and transformation of the use of play and toys by the Nursing staff of a pediatric unit. Method: a study supported by convergent care research, developed between December 2018 and May 2019 with 11 professionals of the Nursing team, through conversation circles. Results: the participants recognize playing as inherent to the child and beneficial in the interaction with the child when hospitalized. They perceive the non-appropriation of structured play in their practices, look for expansion, but identify obstacles associated with little institutional support. From the developments, they decided to insert a puppet and get trained to the use structured play. Conclusions and implications for the practice: The insertion of play in the hospital demands a break with the biomedical model in health and betting on an institutional culture of the recognition of playing. Playing throughout hospitalization integrates fair, humane and comprehensive care, which should be a reason for the Nursing team to fight and guarantee and, for institutions, the duty to provide support, both within the scope of work and permanent education.

Keywords: Child Hospitalized; Pediatric Nursing; Play and Playthings; Professional Competence; Education Continuing

\section{RESUMEN}

Objetivo: analizar el proceso de aprehensión y transformación del uso de juegos y juguetes por parte del personal de Enfermería de una unidad pediátrica. Método: estudio sustentado en investigación de cuidados convergentes, desarrollado entre diciembre de 2018 y mayo de 2019 con 11 profesionales del equipo de Enfermería, a través de círculos de conversación. Resultados: los participantes reconocen el juego como algo inherente al niño y beneficioso en la interacción con el niño cuando está hospitalizado. Perciben la no apropiación del juego estructurado en sus prácticas, buscan expandirlo, pero identifican obstáculos asociados a limitado apoyo institucional. A partir de los desarrollos, decidieron insertar un títere y entrenarse para usar el juego estructurado. Conclusiones e implicaciones para la práctica: la inserción del juego en el hospital exige romper con el modelo biomédico en salud y apostar por una cultura institucional de reconocimiento del juego. Jugar durante toda la hospitalización integra una atención justa, humana e integral, que debe ser motivo de lucha y garantía del equipo de Enfermería, correspondiendo a las instituciones el deber de brindar apoyo, ambos en el ámbito del trabajo y de la educación permanente.

Palabras clave: Niño Hospitalizado; Enfermería Pediátrica; Juego e implementos de juego; Competencia Profesional; Educación Continua. 


\section{INTRODUÇÃO}

A hospitalização imputa, à criança, chances de vivenciar situações traumáticas e estressantes, sobretudo por afastá-la de seu cotidiano e expô-la a um ambiente intimidante, com destaque aos procedimentos diagnósticos e terapêuticos. ${ }^{1}$ A incorporação rotineira do brincar enquanto recurso assistencial da equipe de saúde ameniza este efeito ${ }^{2,3}$ e favorece enfrentamento e adaptação da criança, com destaque para as situações de doença de curso crônico. ${ }^{3}$ Ainda, representa alinhamento com a integralidade e humanização ${ }^{4}$ e reconhecimento dos direitos das crianças. ${ }^{5} \mathrm{~A}$ Organização Mundial da Saúde (OMS) concebe como direito da criança o brincar no hospital e recomenda aos profissionais de saúde sua promoção em todo contexto assistencial. ${ }^{6}$

Apesar das indicativas para o brincar livre e o terapêutico serem considerados nos ambientes hospitalares, ${ }^{2,6}$ sua incorporação nas realidades brasileiras está tímida, pouco efetiva e não tomada enquanto recurso de cuidado do enfermeiro. ${ }^{7} \mathrm{Em}$ muitos contextos, fica restrita à existência de uma brinquedoteca, atendendo a disposição legal. ${ }^{8}$

As crianças expressam o desejo de que o enfermeiro inclua o brincar na prática clínica como forma de interação e comunicação, ${ }^{9-11}$ no entanto, o processo de trabalho de enfermeiros de unidades pediátricas desloca a relevância deste recurso para um lugar secundário. ${ }^{12}$ Desde 2004, o uso do brinquedo/ brinquedo terapêutico é tratado como competência do enfermeiro e tem respaldo legal pelo Conselho Federal de Enfermagem, especificamente descrito na Resolução nำ295/2004, atualizada pela de $\mathrm{n}$-546/2017. ${ }^{13}$

É premente discutir e transformar o lugar do brincar, brinquedo, intervenções lúdicas nas práticas assistenciais de enfermagem. Este estudo explorou o brincar e brinquedo terapêutico nas práticas assistenciais de uma equipe de enfermagem de unidade pediátrica. O objetivo foi de analisar o processo de apreensão e transformação do uso do brincar e brinquedo pela equipe de enfermagem de uma unidade pediátrica.

\section{MÉTODO}

Estudo de abordagem qualitativa, apoiado no referencial metodológico da Pesquisa Convergente Assistencial (PCA), o qual tem sua origem na enfermagem e é voltado à transformação das práticas assistenciais. Este referencial busca desenvolver a atitude crítica e libertadora de profissionais na direção da qualificação do cuidado em saúde. Ele toma questões emergentes da assistência em saúde e visa respostas por aqueles que a produzem e experienciam, ou seja, a prática assistencial e a reflexão acerca dela constituem o dado empírico da pesquisa na direção de resolução de problemas práticos diagnosticados por aqueles que a vivenciam. A PCA é de potencial na geração de compromissos assistenciais ao viabilizar a reconstrução de perspectivas e conhecimentos. ${ }^{14}$

Toma como campo da pesquisa o espaço onde as práticas acontecem e onde o problema elencado ao estudo ocorre,${ }^{14}$ que no caso deste estudo foi uma unidade de internação pediátrica de um hospital de ensino situado em cidade do centro-leste do interior paulista. A unidade possui 12 leitos com taxa de ocupação, segundo informações da enfermeira responsável pelo setor, próxima a $90 \%$ ao longo do período de coleta dos dados deste estudo, dezembro de 2018 a maio de 2019. A equipe de enfermagem da unidade conta com 25 técnicos de enfermagem e 10 enfermeiros, distribuídos em 4 plantões, dois diurnos e dois noturnos, com jornada de trabalho de 36 horas semanais em plantões de 12 horas. A unidade apresenta uma brinquedoteca, cujo acesso é regulado por um profissional da Terapia Ocupacional e um da Psicologia, contudo, o enfermeiro possui a chave deste espaço para uso na necessidade.

Na PCA "o pesquisador deve necessariamente fazer parte do contexto prático, mesmo que temporariamente, durante a pesquisa", ${ }^{14: 844}$ fato contemplado com inserções da primeira autora ao longo do estágio supervisionado curricular de duração de quatro meses e que ocorreu em tempos prévios a coleta de dados do estudo. Ainda, posterior ao estágio, manteve inserções semanais. Cabe destacar que o pesquisador assume, simultaneamente, o papel de pesquisador e participante, ele se integra com os demais participantes com contribuições de informação, reflexão e crítica sobre a prática vivenciada. ${ }^{14}$

Para coleta de dados, adotou-se a roda de conversa pautada na problematização, com aplicação das cinco etapas do Arco de Maguerez na propositura de Berbel. ${ }^{15}$ Todas as rodas de conversa foram conduzidas pela pesquisadora principal, primeira autora deste artigo, com foco no uso do brincar pela equipe de enfermagem. Na primeira roda de conversa, propôs que revisitassem suas práticas e narrassem como entendem que o brincar/brinquedo vem sendo adotado por eles e os determinantes relacionados a esse uso. $O$ exposto nas rodas era tomado para reflexão dialogada e ao término de cada das rodas, de forma coletiva, eram desenvolvidas deliberações para a próxima roda.

Como assinalado acima, a mediação de todas as rodas foi desenvolvida pela primeira autora, a qual recebeu formação para tanto, seja a partir de leituras ou de práticas, quando integrou rodas desenvolvidas pela última autora do estudo com a mesma finalidade. Ainda, após cada roda de conversa desenvolvida para este estudo ocorria uma tutoria entre a primeira, segunda e última autora do artigo.

Alinhado aos estruturantes da PCA, a Educação Permanente (EP) sustentou o estudo, dada a intenção de aprendizagem significativa via reflexão crítica do trabalho, (re)significação do mesmo e seus determinantes, com intenção de transformação dos modos de se fazer atenção à saúde.

O critério de inclusão dos participantes foi ser membro da equipe de enfermagem da unidade pediátrica selecionada para o estudo e, o de exclusão, profissionais afastados por férias e licenças previstas em lei. O convite foi feito pessoalmente a todos da equipe de enfermagem do período diurno pela primeira autora, sendo composta por 6 enfermeiras assistenciais, 12 técnicas de enfermagem e a enfermeira que ocupa cargo de gestora da unidade. Onze das 19 profissionais aceitaram integrar o estudo, sete deles dispostos para vivenciar o processo nas rodas de 
conversa e, outros quatro para momento de devolutiva do construto coletivo. Ou seja, quatro participantes integraram o momento de devolutiva do estudo na instituição fazendo apontamentos e comentários que integraram resultados e discussões. Quanto às recusas, elas estiveram justificadas por desinteresse pelo assunto a ser discutido $(n=2)$, não disponibilidade de tempo $(n=3)$ e preocupação de produzir desconfortos na discussão em roda $(n=1)$, férias ou licença prevista por lei $(n=2)$. Diante do exposto, trata-se de uma amostra de participantes por conveniência, mas que a densidade do exposto e vivenciado favoreceu a identificação de construtos acerca do fenômeno e suas relações, com alcance de saturação acerca do sentido e significado das questões postas em diálogo. ${ }^{16}$

Ao tomar a disponibilidade dos participantes, formaram-se dois grupos que se autodenominaram 'Grupo Lindo', com quatro participantes, e 'Grupo 2', com três participantes. Foram realizadas um total de sete rodas de conversa, três com o 'Grupo Lindo' e quatro com o 'Grupo 2', todas conduzidas pela primeira autora, com duração média de 45 minutos. As rodas foram desenvolvidas no próprio local de trabalho, em horário contrário ao expediente, gravadas em áudio e posteriormente transcritas para análise.

A sistemática de análise dos dados seguiu o recomendado pela PCA, com leitura e releituras das transcrições com vistas aos aspectos globais que sustentaram o diálogo dos participantes. A par dos mesmos, novas leituras e releituras foram desenvolvidas buscando agrupamentos por similaridade temática. Este conjunto de agrupamentos sofreu processos analíticos dedutivos e posteriormente indutivos, culminando em categorias tradutoras do processo. ${ }^{14}$

O estudo foi aprovado por Comitê de Ética em Pesquisa em Seres Humanos sob o parecer n. 3.067.479 de 09/12/2018, CAAE n. 03476018.4.0000.5504. Todos os preceitos éticos foram respeitados. Os excertos estão identificados pelo nome do grupo referente, seguido da palavra "roda" e um número, tradutor da roda de conversa no qual emergiu aquele dado.

\section{RESULTADOS}

Do processo de análise dos dados resultaram três categorias temáticas: "Entre o saber e o brincar sistemático: caminhos a lapidar", "Gestão, pares e uso do brincar" e "Projetando caminhos à transformação da prática". Os motivos que impulsionam e recolhem os participantes, na busca da transformação de suas práticas, foram tratados sob uma tessitura de idas e vindas apreciativas dos aspectos envolvidos e suas relações. Apesar dos limitadores, pactuam apostas na transformação das práticas.

A categoria "Entre o saber e o brincar sistemático: caminhos a lapidar" trata das concepções que ancoram o reconhecimento do brincar e a necessidade de ultrapassar os intervenientes de sua concretude. São elas: (1) o brincar é inerente à criança, é linguagem por meio da qual ela expressa suas necessidades; (2) a hospitalização e o adoecimento trazem impacto à criança e ao profissional cabe seu acolhimento, quando o brincar é recurso; (3) as práticas do cotidiano da enfermagem repercutem em imagem negativa, a qual tem no brincar possibilidade de transformação e, (4) revelam-se intervenientes que dificultam a concretude do brinquedo pela equipe:

O lúdico é inerente ao trabalho em Pediatria, porque está dentro daquilo que é do meu público-alvo. [...] Na verdade, a gente entra no mundo infantil, não que a gente traz a criança para o nosso mundo, a gente entra no mundo da criança. [...] Então, fico pensando que, às vezes, a gente acha que a gente faz $e$, na verdade, a gente tem muito mais para fazer de lúdico. E até no dia-a-dia passa batido e não fez. Acho que será muito bom isso aqui (pesquisa) (Grupo 2 - roda 1)

Consideram a criança enquanto pessoa, com olhar diferente do adulto, com capacidade para revelar percepções e necessidades. Assinalam que ao vivenciar relações de abertura, interesse e esforços para apreender seu olhar, revela-se. O brincar e a atitude lúdica do adulto favorecem estas relações.

Eu acho que criança tem um lado que a gente, muitas vezes, não vê. Elas veem o mundo de uma outra maneira e, com isso, a gente aprende coisas com eles sim, embora sejam crianças. Coisas dela mesmo. Quando você usa o brincar você tem um momento de interação ali, você descobre coisas novas, você aprende com as crianças coisas delas. (Grupo 2 - roda 1 )

O brincar é uma ação com a qual a criança se envolve naturalmente, diante de um mínimo estímulo ela já se direciona a esta atividade. Crianças gostam de estar em ambientes com cores, com decoração infantil, com atividades para ela se envolver livremente, retratar seus desejos, ou seja, brincar. Reconhecem a ambiência lúdica como espaço familiar às crianças.

Outra coisa legal também foram os desenhos (decoração da unidade), porque não tinha esses desenhos. Ficou fofo! Aliás, elas (crianças) pintaram a parede, você viu a boneca? Quando a gente (profissionais) viu, a boneca já estava pronta! (todas riem). [...] A mãe ficou nervosa e chateada que ela (criança) fez aquilo (desenhou na parede). Aí eu falei: "Mãe, fica calma, olha a parede, ela achou que ela também podia, porque ela está toda riscada!". [...] Eu olho aquela parede e eu me sinto feliz! Porque eu acho que elas (crianças) conseguiram se expressar. Se representar naquele desenho. Eu acho que não devia pintar essa parede, essa parede devia ficar assim mesmo: "Olha! Tem criança aqui!". Entendeu? (Grupo Lindo - roda 1)

O brincar vai sendo discutido como uma prática assistencial Identificam a si profissionais com esforços de acolhimento, inclusive a partir do uso do brincar e revisitaram o uso que fazem, identificaram prevalência da adoção de músicas e desenhos com intenções de colaboração e distração durante procedimentos 
e avaliações. Reforçam deterem um atitudinal lúdico intrínseco e que muitas das estratégias que usam é de conhecimento popular, de uso comum.

Então o profissional que já está na Pediatria, ele já faz muitas coisas. Já tem habilidades no manejo da criança, do jeitinho de falar, da brincadeira que nem precisa de nada assim de objeto, mas que consegue com o jeito dele conquistar a criança. Então esse profissional, ele já vem munido de algumas características pessoais e profissionais que facilitam, né? Do profissional adulto para o lúdico que leva à criança. (Grupo 2 - roda 1)

Toda vez que você entra para fazer um sinal, para fazer uma medicação, você tem que distrair, brincar, com a criança. Põe uma musiquinha, brinca do esconde, por exemplo, a gente está lá tentando ver a respiração da criança. Aí a criança está agitada, aí a gente (pensa) é pouca coisa, pouco tempo, mas a gente bota a musiquinha e aí acalma a criança! (Grupo Lindo - roda 2)

Mas agora que me veio que, realmente, a gente usa música. (risos) a gente usa a música nos sinais vitais, acho que é uma das estratégias que a equipe acaba usando, para conseguir fazer alguns procedimentos. [...]A gente traz músicas que são de conhecimento popular porque, realmente, faz com que essas crianças fiquem mais calmas. [...] A gente faz brincadeiras com as crianças, no próprio procedimento, quando você brinca com a criança ou os desenhos, quando a gente traz desenhos para elas. (Grupo 2 - roda 1)

No fim, eu acho que a gente faz bastante coisa. Não parece quando a gente pensa e quando a gente fala, mas quando escreve, a gente até que tem estratégias (lúdicas) interessantes que a gente já coloca em prática. (Grupo Lindo - roda 2)

Foram constantemente reforçando a necessidade de incorporar o brincar de forma estruturada no ambiente e nas práticas hospitalares, sob o destaque da possibilidade de revelações relativas à singularidade da criança e de suas necessidades. Com esta intenção, reconhecem incipiências e deflagram a não sistemática da prática, ponderaram o real alinhamento delas com a ideia de acolhimento na singularidade de cada criança e sua situação.

Eu acho que dá para ser planejado também (uso do brincar), e aínesse ponto a gente faz pouco. [...] A criança está internada, aparece uma demanda, demandas que a gente precisa conversar com a criança, investigar melhor algum ponto, e aí a gente pode usar o brincar para isso, né? Então, para avaliar algumas coisas, porque as crianças brincando, elas falam coisas que elas não falam se elas não estiverem brincando. [...] Eu, como enfermeira, usei pouco essa estratégia de brincar planejado, tendo a intenção realmente de investigar ou de tratar alguma coisa na criança. Mas que existe essa possibilidade, eu acho que existe. (Grupo Lindo - roda 3)

O profissional precisa se envolver, porque senão, não vai dar certo! Até o brincar pode sair de forma mecânica! (pensa) Acredito que tem a ver sim com a relação que eu faço de como a criança enxerga o mundo, os profissionais de saúde e o ambiente hospitalar. Então, eu preciso saber em que mundo essa criança vive. Tudo isto é colocado em jogo no brincar, na relação com ela. Então eu acho que isso está extremamente relacionado com como eu vejo a criança. Além de entender o que é ser criança e como ela enxerga, eu também tenho que saber as especificidades. E a humanização no atendimento, ela envolve realmente isso, de você entender o que é ser criança, você entender porque ela está daquele jeito, porque ela aceita ou não e ter estratégias estruturadas de trabalho, como o brincar. Algo estruturado, isto falta. (Grupo 2- roda 4)

A discussão voltada a um uso mais estruturado e ampliado do brincar, a falta de tempo é apontada de maneira articulada a uma concepção inicial de ser um fazer 'extra', não integrante da responsabilidade do fazer da enfermagem e o dissociam do papel do enfermeiro, como se essa atividade não constasse do rol de suas competências.

Seria interessante, mas a gente não tem disponibilidade de tempo para isso. Porque tem a rotina, que a gente não tem que deixar de fazer os cuidados, mas assim, eu acho que seria interessante associar isso. Só que é a questão do tempo, que nem a (nome enfermeira) falou, a gente também não pode deixar de fazer as nossas responsabilidades para ficar brincando com as crianças. É, eu acho que uma das questões que eu vejo é a enfermagem, ela é, realmente, muito sobrecarregada com outros papeis! (Grupo 2 - roda 1 )

Depositam, inicialmente, o brincar a ações próprias de outras profissões, mas os diálogos nas rodas realocam o brincar enquanto uma ação também própria à enfermagem. Reconhecem que ao manter a ocupação fundamental da criança, o brincar, ela passa a dar sentido de normalidade à vida, mesmo vivenciando a rotina do hospital.

Eu acho que a gente trabalha um pouco menos com o brincar (comparando com a terapia ocupacional e psicologia), a nossa interação de brinquedo com a criança é limitada. Isso se limita a alguns membros da equipe como, por exemplo, o terapeuta ocupacional, que é o que mais acaba utilizando. E a gente percebe que, as crianças adoram o terapeuta ocupacional porque é um profissional que vai fazer seu atendimento baseado em brinquedos, em estratégias lúdicas. [...]Então é uma 
coisa que precisava casar mesmo. Então, eu tenho que fazer tal coisa, mas eu também tenho uma outra parte do meu trabalho que é trabalhar o lúdico. Até porque, muitas vezes, a gente tem diversas demandas. Porque o profissional de enfermagem tem uma demanda muito alta! Então, dia que tem muita criança internada, que tem vários pacientes doentes, tem várias medicações. São responsabilidades muito altas. (Grupo 2 - roda 1)

No hospital ela (criança) saiu do âmbito dela, foi para o hospital. Só que no hospital a gente traz o brincar, traz o brinquedo, traz as dinâmicas. $E$ isso faz ela voltar para o ambiente dela ou ser mais ou menos o mais próximo possivel do ambiente dela! [...] Acho que, na verdade, nada mais necessário do que mantê-la (a criança) no seu ambiente normal, no seu ambiente natural e na sua ocupação habitual, né? O brincar. (Grupo 2 - roda 4)

As discussões debruçaram-se sobre as construções sociais relacionadas ao brincar e ao hospital/hospitalização/enfermagem. Identificaram que a imagem que a criança estabelece delas tem relação direta com as ações que efetuam e que essas refletem o foco assistencial da unidade/hospital e o papel depositado à enfermagem. Reconhecem que a criança, ao brincar com o enfermeiro, (re)significa a imagem dele para alguém mais acolhedor e brincante.

As crianças olham a gente com outros olhos depois disso (do uso do brincar). Exato! É olhar e falar assim: "Ah, é aquela moça que veio brincar aqui, então eu já não vou ter mais medo dela. Eu já não vou olhar ela como se fosse um monstro que só vai picar, fazer procedimento dolorido.". Tipo, uma punção venosa, dar injeção. Acabam percebendo que os profissionais também estão engajados em algumas atitudes lúdicas. Tem criança que vê a gente de branco e já começa a chorar. (Grupo 2 - roda 1)

A gente imprime desenhos para eles (crianças) pintarem e eles adoram. Tanto que, às vezes, na hora de ir embora da alta, entregam cartinhas com desenhos para gente. Assim, mostra ao mundo que o hospital não é aquele bicho de sete cabeças que você, que elas (crianças) veem. Até algo que eu acho muito interessante as crianças desenhando para os funcionários! Isso é muito bom, a gente vê que as crianças sorriem, fazem desenhos para gente e até ajuda no procedimento. Eugosto disso! (Grupo 2 - roda 1)

Vão clarificando cada vez mais que, na realidade onde atuam, o brincar não está posto a enfermagem e que ele tem um lugar secundário em relação à execução de procedimentos vinculados ao tratamento médico. Desejam transformação, além de identificar no brincar a edificação de imagem mais positiva. Assim, reforçam a necessidade de assunção do brincar como própria da enfermagem também, destacando que é algo bom para todos, traz reconhecimento e motivação ao profissional.

Brincar é uma estratégia de trabalho em Pediatria, inclusive da enfermagem. O profissional que usa o brincar e interage com a criança aprende com ela e é simultaneamente motivado. Usar o brincar é motivador. É bom pra gente também quanto profissional e quanto pessoa também, para levar para a vida pessoal.(uma participante intervém) Eu acho que isso é bom para ambos, para as crianças e para pessoa que está fazendo. É uma terapia de grupo! (em tom de brincadeira) (todas riem). (Grupo 2 - roda 4)

Neste contexto, debruçam-se sobre a concepção que a própria enfermagem faz acerca do uso do brincar e consideram que disseminar o entendimento na própria categoria é fundamental para ampliar seu uso de forma mais intencionada e deliberada.

Então isso (refletir sobre o uso que estão fazendo do brincar/lúdico) é uma estratégia para reforçar o trabalho da equipe de enfermagem. Que eu acho que é uma das coisas que a gente precisa trabalhar muito. (silêncio) $E$ a gente percebe que a equipe de enfermagem teria um espaço amplo nisso (uso do lúdico e do brincar), né? Porque, realmente, é algo que é extremamente importante, e a enfermagem é a que mais trabalha com a criança. Mas, ainda assim, é insuficiente, porque, realmente, para gente sobra uma parte muito ruim, que é necessária, mas que também para criança é pesado. (Grupo 2 - roda 4)

A categoria "Gestão, pares e o uso do brincar e brinquedo" trata das reflexões acerca da viabilidade do uso do brincar, em especial quando da alta ocupação da unidade, períodos de sazonalidade. Denunciam não identificarem grandes esforços da gestão institucional olhar de forma diferenciada estes tempos. $\mathrm{O}$ cansaço e estresse sentido são referidos como condições que restringem envolvimento com a criança e, desse modo, o uso do brincar e o atitudinal lúdico portado. Sentem-se frustradas frente ao desdobramento disto para a qualidade da assistência de enfermagem. O grupo Lindo tematizou esta questão com maior intensidade, sendo refletido em maior recolhimento de suas apostas de transformação.

A gente tem uns períodos de sazonalidade [...] Aí fala-se em humanização. Você não vai ter como ter humanização com a criança e com a mãe se você não está tendo humanização com você! Você está trabalhando sobrecarregado e isso vaiacabando com a sua disposição. Porque você acaba ficando frustrado, não está fazendo do jeito que você queria, você sabe que você é melhor que isso. Você pode prestar um atendimento melhor que isso. Cansada porque você está sobrecarregada. Então é meio traumático. [...] difícil usar o brincar nestas condições. (Grupo Lindo - roda 1) 
Compõe o cenário restritivo ao brincar a filosofia assistencial institucional, centrada no adoecimento, com uma concepção de ser o uso do brincar pela enfermagem não integrado, um fazer algo a mais em um movimento dissociado do cuidado sistematizado, no qual a abordagem tecnicista e burocrática prevalece na relação com o outro.

Muitas vezes, o que nos é cobrado (institucionalmente) são questões muito burocráticas e muito técnicas. Óbvio que existe a questão da segurança do paciente, essas questões são extremamente importantes, mas eu sou cobrada por técnicas que eu tenho que fazer, técnicas precisas. Pelas quantidades de procedimentos que eu faço, pela quantidade de procedimentos burocráticos que a gente acaba fazendo. Mas, ainda assim, a gente tem uma questão histórica muito técnica. (sobre do hospital) E, por isso que, às vezes, parece que a gente tem que encaixar a questão lúdica. [...] Então, às vezes, a gente pensa no lúdico, ou outras questões dentro do nosso processo de trabalho como um trabalho a mais, $e$ não como um trabalho que já é meu, né? Então eu tento trabalhar com a criança, o lúdico já tem que estar no meu trabalho, mas, muitas vezes, pelo histórico tecnicista, a gente acaba deixando isso um pouco de lado (Grupo 2 - roda 1$)$

Na categoria "Projetando caminhos à transformação da prática", a centralidade foi na discussão que reforça a relevância ao acolhimento da criança enquanto ser lúdico e seu desdobramento ao reconhecimento do profissional, com renovação do credo nestas balizas assistenciais. Retomam a coesão da equipe de enfermagem para manterem a aposta na transformação de suas práticas em termos de uso do brincar. Dão visibilidade a percepção de que o apoio incipiente da gestão afeta, mas não pode tolhê-las no movimento.

Deste modo, selecionam como encaminhamentos: (1) inserir o fantoche nas práticas de enfermagem, recurso de maior interesse do Grupo 2, no qual uma das participantes comprou um conjunto de fantoches e doou à unidade; (2) desenvolver formação em brinquedo diretivo e brinquedo terapêutico à equipe de enfermagem da unidade; (3) apostar, individualmente, em um uso mais deliberado e intencional do brincar nas práticas assistenciais junto da criança.

Se a equipe é uma equipe que tem coesão sobre o assunto e que pensa, por exemplo: "Ah, vamos criar um grupo de fantoches." Isso, realmente, eu acho que motiva para outras estratégias lúdicas. Então, o grupo de fantoche foi um 'start' inicial, mas ele foi um disparador para várias outras estratégias. [...] A equipe é coesa, são pessoas que já têm afinidades, nós trabalhamos juntas há bastante tempo, então eu acho que isso facilita muito o trabalho. [...] Porque eu acho que a consciência de que o uso de brinquedos, da brinquedoteca, do uso do lúdico é importante para Pediatria, eu acho que todo mundo que trabalha com Pediatria tem essa consciência. (Grupo 2 - roda 2)

E eu acho também que o brincar terapêutico, ele é algo que realmente necessitaria de uma capacitação melhor para equipe. [...] Também tem essa questão... (Grupo Lindo - roda 3)

Solicitaram, na linha de formação, oportunidade de compartilhar com outras enfermeiras/equipe de enfermagem experiências no uso de brincar. Como encaminhamento, compartilhou-se vídeo gravado junto à última autora deste estudo sobre suas vivências com o brincar enquanto enfermeira. Ele foi assistido individualmente e dialogado na roda 3 de ambos os grupos. $O$ efeito foi de motivação e ponderação de novas possibilidades de uso do brincar e brinquedo.

Porque a gente percebe que foi algo que na experiência dela (vídeo convidada externa) deu muito certo. Ea nossa tendência, ao ver uma experiência que deu certo, é utilizála também. Então eu acho que fortalece a ideia. Depois que eu vi esse vídeo, mudou muito a minha maneira de pensar. Mas assim, eu acho que abre a mente da gente você vendo pessoas que já tiveram experiências sobre isso [...] Eu gostei muito desse vídeo e eu acho que a minha cabeça deu uma expandida. Eu me lembro que quando a gente assistiu, eu fiquei: "Uau!" A sensação que eu tive foi exatamente essa! (risos). [...]E motivação, eu achei que eu me senti motivada em pensar nas possibilidades, no que aconteceu com ela, nas experiências que ela passou e nas coisas que a gente passa no dia-a-dia. Eu gostei muito. (Grupo 2 - roda 4)

\section{DISCUSSÃO}

A literatura ressalta que o brincar é fundamental para o cuidado pleno e humanizado. Por meio desse instrumento o diálogo e o relacionamento entre criança e equipe de enfermagem são potencializados, gerando segurança e conforto, além de ajudar a criança a superar suas fantasias negativas e aliviar a tensão, seus medos e ansiedade. ${ }^{17} \mathrm{~A}$ hospitalização impacta a criança e sua família e requer do profissional compreensão não somente da doença, mas também dos demais impactos, quando é essencial incluir a criança e seus apontamentos. ${ }^{11}$

Com esse entendimento e com a concepção de ser o brincar inerente à infância e meio de expressão por excelência, os participantes vivenciam um dilema entre saber o que devem fazer e aquilo que conseguem concretizar, conhecem os benefícios do brincar sistemático à criança e vivenciam as adversidades que impedem sua concretude, dentre os quais destaca-se o modelo vigente de assistência hospitalar.

Este impõe em termos de responsabilidade e demandas do enfermeiro, o tecnicismo e a medicalização do cuidado, contudo, 
os participantes percebem-se na necessidade de superação desse modelo de cuidado. Do profissional de enfermagem espera-se que faça o movimento em direção à criança, com reconhecimento da atitude lúdica e do brincar/brinquedo como recurso de aproximação, dado as chances de diálogo entre o profissional e a criança ocorrerem a partir dele.

O brincar e o brinquedo terapêutico são recursos da enfermagem pediátrica para o enfrentamento do processo de adoecimento e hospitalização, ${ }^{18}$ favorecem à criança lidar com as adversidades, além de serem meios de comunicação que revelam singularidade e proporcionam confiança entre profissionalcriança-familiares. As próprias famílias reconhecem a força do brinquedo terapêutico como aliado para a criança sentir-se mais segura diante da admissão hospitalar e dos medos inerentes à situação de hospitalização. ${ }^{19,20}$

O brincar manifesta-se como uma demanda própria da infância e o enfermeiro, ao valorar a assistência integral e humanística, naturalmente recorre às estratégias lúdicas, ao brincar e ao brinquedo, movimentados a partir de suas habilidades criativas, ${ }^{21}$ aspecto identificado também nas participantes deste estudo. No entanto, as pesquisas indicam que apesar disto, sua inclusão na assistência não é rotineira, o que denota certa desvalorização na incorporação desses conhecimento ${ }^{17}$ ou limites para utilizálos. No caso deste estudo, o modelo de cuidado vigente e o não reconhecimento de estar o brincar entre as práticas genuínas e integrantes do cuidado de enfermagem foi um aspecto limitador.

Quando o fazer da enfermagem fica restrito a executar procedimentos e ações consideradas invasivas e é reduzido a incumbências técnicas e burocráticas, o estabelecimento da interação com a criança é limitado e a construção de vínculos terapêuticos é dificultada. Conforme apontado pelos participantes, culturalmente a criança faz uma imagem negativa do profissional de enfermagem como sendo ele o executor de procedimentos dolorosos e desagradáveis e vislumbram na adoção do brincar e do brinquedo a possibilidade para a transformação desta imagem para uma mais positiva.

O brincar e o brinquedo favorecem um relacionamento profissional-criança mais pleno e qualificam a comunicação, uma vez que é linguagem infantil, a criança se expressa e se mostra enquanto brinca. Em estudo que abordou a concepção da criança hospitalizada em relação ao cuidado de enfermagem, foi salientada a desaprovação dos escolares em relação aos profissionais que não explicavam os procedimentos e que agiram de forma autoritária; afirmaram que, para cuidar de criança, os profissionais precisam ser engraçados e brincar, o que denota a necessidade de incluir o lúdico na assistência de enfermagem. ${ }^{11}$

A adoção do brinquedo revelou-se tímida na realidade dos participantes, destacou-se a centralidade depositada às práticas rotineiras de internação e no tratamento da doença da criança, quando o brincar e a brincadeira ficam em segundo plano. Isto confirma que, embora a literatura seja vasta no que se refere às vantagens e benefícios do brincar no hospital, ele é pouco empregado no cotidiano assistencial da enfermagem, sob alegação de falta de tempo e o despreparo para o uso do brinquedo terapêutico, ${ }^{17}$ também presentes neste estudo. Em relação ao brinquedo terapêutico, apesar da regularização e incentivo para que o tema seja inserido na formação profissional, existe uma inconsistência dessa questão ao redor do mundo, tanto em termos de qualidade quanto de conteúdo. ${ }^{22}$

A escassez de infraestrutura, força de trabalho capacitada e a pressão do tempo podem fazer com que as intervenções terapêuticas por meio do brincar sejam pouco viáveis em locais com recursos limitados, ${ }^{22}$ revelando o impacto da cultura institucional no uso do brincar e brinquedo pela enfermagem. Assim, sugerimos que a perspectiva de gestores seja apreendida em estudos futuros, em especial no que tange ao entendimento e suporte sobre o uso do brincar.

Neste estudo prevaleceu o uso de uma atitude lúdica pela enfermagem, em especial com exploração do brincar na interação com a criança por meio do cantar, de mímicas com as mãos ou do mostrar vídeos de músicas via celular. $\mathrm{O}$ uso intencionava colaboração durante o procedimento via distração, o que corrobora com a literatura, na qual a distração de forma sistematizada tem sido efetiva na redução da dor e do medo diante de procedimentos dolorosos, ${ }^{18}$ no entanto, sem considerar suas funções de estímulos no âmbito do desenvolvimento motor e cognitivo.

Em um movimento mais avançado das reflexões nas rodas de conversa, o envolvimento como condição necessária para se aproximar da criança e conhecer suas necessidades desponta e fortalece o desejo de ter maior consciência e intencionalidade no uso do brincar; de criar vínculo e minimizar o impacto da internação. ${ }^{23}$ Discorrem, ao longo das discussões, a utilização do brincar estruturado e intencional, sobre sua viabilidade, quando tematizam o fantoche e seus benefícios, bem como o brinquedo terapêutico.

Em relação ao uso do fantoche, estudos o evidenciam como um excelente recurso a ser utilizado por profissionais de saúde com a intenção de promover comunicação, permitindo compreender as reações e sentimentos manifestados pelas crianças e encorajando relacionamento de aproximação entre profissionais e crianças. ${ }^{24}$

Contudo, os participantes revelam necessidade de ampliar conhecimentos e competências para sua adoção, quando desejam formação continuada. Assim, questionamos: 'Estão as formações técnicas e de graduação tematizando o assunto? Em que medida e profundidade? E as formações em serviço, como estão tomando esta questão?'. Sugerimos explorações nestas direções.

Ainda, cabe mencionar sobre a não tematização aprofundada da brinquedoteca pelos participantes, com questionamento se a percebem como um lugar para a enfermagem. Remetê-la a usos exclusivos de categorias profissionais é negar a essência do espaço e sua propositura e garantia legal ${ }^{8} \mathrm{com}$ propósito de proteger o brincar, ocupação natural da criança, durante o período de hospitalização.

Segundo estudos, na prática diária dos profissionais de enfermagem, em virtude da necessidade de atender a demandas 
fisiológicas da criança, dedicam pouca ou nenhuma atenção às questões psicológicas da mesma, o que faz com que o uso da brinquedoteca seja, muitas vezes, limitado. ${ }^{25}$ É importante ressaltar que apesar de sua importância, a brinquedoteca não deve ser o único espaço em que as atividades de brincar sejam desenvolvidas, pois condicionaria $\mathrm{o}$ ato a momentos restritos e fragmentados. ${ }^{26}$

Neste estudo, os participantes reconheceram e valoraram a ambiência da unidade pediátrica, compreendendo que um ambiente hospitalar no qual há atendimento pediátrico deve ser diferenciado para que se torne mais acolhedor e menos assustador à criança. Defendem que este ambiente seja mais colorido, alegre, com temas lúdicos e desenhos, de forma a anunciar e aludir ao infantil. Revisão da literatura destaca ser imperativo a construção de ambiências acolhedoras, estruturadas para assistir a criança de forma integral, proporcionando o melhor enfrentamento da hospitalização e garantindo o brincar enquanto um direito da criança durante a hospitalização. ${ }^{27}$

Por fim, exaltamos o fato de que o brincar ao longo da hospitalização, tanto na modalidade recreativa quanto terapêutica, integra um cuidado justo, humano e integral. A equipe de enfermagem está entre os profissionais que devem lutar e garantir esta incorporação por meio do desenvolvimento da competência lúdica. ${ }^{21} \mathrm{E}$, às instituições cabe o dever de dar suporte, tanto no âmbito dos processos de trabalho, quanto no da educação permanente e todas as questões tematizadas neste estudo.

\section{CONCLUSÃO E IMPLICAÇÕES PARA A PRÁTICA}

O estudo descreveu o reconhecimento e desejo dos participantes no uso do brincar em suas práticas de cuidado, porém o contexto institucional pouco valorizador deste estruturante assistencial tolhe-as ao uso da atitude lúdica, com vistas à colaboração e distração da criança em procedimentos.

Tomar consciência deste cenário os propulsionou na crítica e luta pela transformação da situação. A propositura de avanços ficou circunscrita a autonomia da equipe de enfermagem, quando decidiram por incorporar o fantoche e apostar na formação para o uso do brinquedo diretivo e terapêutico. Porém, anunciam desejos de tensionar a filosofia assistencial, questão iniciada pelas pesquisadoras na devolutiva do estudo à instituição. A cultura do brincar em hospitais ainda guarda um hiato em termos de articulação com práticas assistenciais, quando formações críticas estão indicadas.

O referencial metodológico selecionado foi potente ao objetivo do estudo, uma vez que a abertura e disposição dos participantes em fazerem revelações e apontamentos permitiu que aspectos relativos ao contexto viessem à tona sinalizando importantes nós críticos para a efetivação de práticas de incorporação do brincar e brinquedo. Possibilitou a aplicação prática da essência da educação permanente em saúde, promovendo a geração de conhecimento científico a partir da realidade vivenciada, favorecendo atitudinal profissional em prol da melhoria contínua e promovendo o questionamento crítico das práticas, tal como a discussão colaborativa e enriquecedora e a aprendizagem significativa dos envolvidos.

Destaca-se o número limitado de participantes, mas a densidade do processo movimentado contrapôs esse aspecto, permitindo que o revelado seja tomado nas considerações de outros cenários de hospitalização pediátrica. De todo modo, recomendam-se que outras pesquisas sejam realizadas sob o enfoque dos propulsores e intervenientes ao uso do brincar pela equipe de enfermagem, em especial, enfermeiros.

\section{FINANCIAMENTO}

Bolsa de Iniciação Científica - FAPESP - Processo n²018/14455-3. Concedida a estudante Maria Izabel Sartori Claus, sob a orientação da docente Monika Wernet. "O presente trabalho contou com apoio da Coordenação de Aperfeiçoamento de Pessoal de Nível Superior - Brasil (CAPES) - Código de Financiamento 001".

\section{CONTRIBUIÇÕES DOS AUTORES}

Desenho do estudo. Maria Izabel Sartori Claus. Edmara Bazoni Soares Maia. Monika Wernet.

Coleta ou produção dos dados. Maria Izabel Sartori Claus. Edmara Bazoni Soares Maia. Monika Wernet.

Análise de dados. Maria Izabel Sartori Claus. Edmara Bazoni Soares Maia. Monika Wernet. Ana Izaura Basto de Oliveira. Aline Landim Ramos. Patrícia Luciana Moreira Dias.

Interpretação dos resultados. Maria Izabel Sartori Claus. Edmara Bazoni Soares Maia. Monika Wernet. Ana Izaura Basto de Oliveira. Aline Landim Ramos. Patrícia Luciana Moreira Dias.

Redação e revisão crítica do manuscrito. Maria Izabel Sartori Claus. Edmara Bazoni Soares Maia. Monika Wernet Ana Izaura Basto de Oliveira. Aline Landim Ramos. Patrícia Luciana Moreira Dias.

Aprovação da versão final do artigo. Maria lzabel Sartori Claus. Edmara Bazoni Soares Maia. Ana Izaura Basto de Oliveira. Aline Landim Ramos. Patrícia Luciana Moreira Dias. Monika Wernet.

Responsabilidade por todos os aspectos do conteúdo e a integridade do artigo publicado. Maria Izabel Sartori Claus. Edmara Bazoni Soares Maia. Ana Izaura Basto de Oliveira. Aline Landim Ramos. Patrícia Luciana Moreira Dias. Monika Wernet.

\section{EDITOR ASSOCIADO}

Beatriz Toso

\section{REFERÊNCIAS}

1. Rokach A. Psychological, emotional and physical experiences of hospitalized children. Clin Case Rep Rev. 2016;2(4):399-401. http:// dx.doi.org/10.15761/CCRR.1000227.

2. Al Yateem N, Rossiter RC. Unstructured play for anxiety in pediatric inpatient care. J Spec Pediatr Nurs. 2017;22(1):e12166. http://dx.doi. org/10.1111/jspn.12166. 
3. Nijhof SL, Vinkers CH, Van Geelen SM, Duijff SN, Achterberg EJM, Van der Net $\mathrm{J}$ et al. Healthy play, better coping: the importance of play for the development of children in health and disease. Neurosci Biobehav Rev. 2018;95:421-9. http://dx.doi.org/10.1016/j.neubiorev.2018.09.024

4. Fioreti FCCF, Manzo BF, Regino AFF. A ludoterapia e a criança hospitalizada na perspectiva dos pais. Rev Min Enferm. 2016;20:e974

5. European Association of Children at Hospital. The Europ 10 articles of the EACH Charter. 2016 [citado 2020 ago 20]. Disponível em: http:// www.each-for-sick-children.org/each-charter/the-10-articles-of-theeach-charter.html

6. World Health Organization. Standards for improving the quality of care for children and young adolescents in health facilities [Internet]. Geneva: WHO; 2018. 128 p. [citado 2020 ago 20]. Disponível em: http://apps. who.int/iris/bitstream/handle/10665/272346/9789241565554-eng. pdf?ua $=1$

7. Baldan JM, Santos CP, Matos APK, Wernet M. Introduction of play/ playthings in the assistance practice to the hospitalized child: nurses' trajectory. Cienc Cuid Saude. 2014;13(2):228-35.

8. Lei no 11.104, de 21 de março de 2005 (BR). Dispõe sobre a obrigatoriedade de instalação de brinquedotecas nas unidades de saúde que ofereçam atendimento pediátrico em regime de internação. Diário Oficial da União [periódico na internet], Brasília (DF), 22 mar 2005 [citado 14 set 2020]. Disponível em: http://www.planalto.gov.br/ ccivil_03/_Ato20042006/2005/Lei/L11104.htm

9. Boztepe H, Çinar S, Ay A. Schol-age children's perceptions of the hospital experience. J Child Health Care. 2017;21(2):162-70. http:// dx.doi.org/10.1177/1367493517690454.

10. Comparcini D, Simonetti V, Tomietto M, Leino-Kilpi H, Pelander T, Cicolini G. Children's perceptions about the quality of pediatric nursing care: a large multicenter cross-sectional study. J Nurs Scholarsh. 2018;50(3):287-95. http://dx.doi.org/10.1111/jnu.12381.

11. Santos PM, Silva LF, Depianti JRB, Cursino EG, Ribeiro CA. Nursing care through the perception of hospitalized children. Rev Bras Enferm. 2016;69(4):603-9. http://dx.doi.org/10.1590/0034-7167.2016690405i.

12. Leite TMC, Vergílio MSTG, Silva EM. Processo de trabalho do enfermeiro pediatra: uma realidade a ser transformada. Rev Rene. 2017;18(1):2634. http://dx.doi.org/10.15253/2175-6783.2017000100005.

13. Resolução COFEN no 0546, de 9 de maio de 2017 (BR). Atualiza norma para utilização da técnica do Brinquedo/Brinquedo Terapêutico pela equipe de enfermagem na assistência à criança hospitalizada. Diário Oficial da União [periódico na internet], Brasília (DF), 17 maio 2017 [citado 2020 ago 20]. Disponível em: www.cofen.gov.br/resolucaocofen-no-05462017_52036.html

14. Trentini M, Paim L, Silva DMGV. Pesquisa Convergente Assistencial: delineamento provocador de mudanças nas práticas de saúde. 3. ed. Porto Alegre: Moriá; 2014.
15. Berbel NAN. A metodologia da problematização com o Arco de Maguerez: uma reflexão teórico-epistemológica. Londrina: EDUEL; 2012.

16. Hennink MM, Kaiser BK, Marconi VC. Code Saturation Versus Meaning Saturation: How Many Interviews Are Enough? Qual Health Res. 2017;27(4):591-608. http://dx.doi.org/10.1177/1049732316665344.

17. Costa DTL, Veríssimo MDLÓR, Toriyama ATM, de Siqueira Sigaud CH.O brincar na assistência de enfermagem à criança-revisão integrativa. Rev Soc Bras Enferm Ped [Internet]. 2016; [citado 2020 ago 20];16(1):36-43 Disponível em: https://sobep.org.br/revista/images/stories/pdf-revista/ vol16-n1/vol_16_n_1-artigo-de-revisao-1.pdf

18. Drape K, Greenshields S. Using play as a distraction technique for children undergoing medical procedures. Br J Nurs. 2020;29(3):142-3. http://dx.doi.org/10.12968/bjon.2020.29.3.142.

19. Kapkın G, Manav G, Karayağız Muslu G. Effect of therapeutic play methods on hospitalized children in turkey: a systematic review. Erciyes Med J.2020;42(2):127-31. http://dx.doi.org/10.14744/etd.2019.94940.

20. Aranha BF, Souza MA, Pedroso GER, Maia EBS, Melo LL. Utilizando o brinquedo terapêutico instrucional durante a admissão de crianças no hospital: percepção da família. Rev Gaúcha Enferm. 2020;41:e20180413. http://dx.doi.org/10.1590/1983-1447.2020.20180413.

21. Maia EBS, La Banca RO, Nascimento LC, Schultz LF, Carvalho Furtado $M C$, Sulino MC et al. Nurses' perspectives on acquiring play-based competence through an online course: a focus group study in Brazil. $J$ Pediatr Nurs. 2020;1:10-5. PMid:33082034.

22. Shrinivasa B, Bukhari M, Ragesh G, Hamza A. Therapeutic intervention for children through play: an overview. Arch Ment Health. 2018;19(2):829. http://dx.doi.org/10.4103/AMH.AMH_34_18.

23. Falke, A.C.S., Milbrath, V.M. and Freitag, V.L., 2018. Estratégias utilizadas pelos profissionais da enfermagem na Abordagem à criança hospitalizada. Rev Contexto Saúde, vol. 18, no. 34, pp. 9-14. http:// dx.doi.org/10.21527/2176-7114.2018.34.9-14.

24. Sposito AMP, de Montigny F, Sparapani VDC, Lima RAG, Silva-Rodrigues FM, Pfeifer LI et al. Puppets as a strategy for communication with Brazilian children with cancer. Nurs Health Sci. 2016;18(1):30-7. http:// dx.doi.org/10.1111/nhs.12222.

25. Rocha MCP, Dias ECV, Fossa AM, Horibe TM. O significado do brincar e da brinquedoteca para a criança hospitalizada na visão da equipe de enfermagem. Saúde em Revista. 2015;15(40):15-23. http://dx.doi. org/10.15600/2238-1244/sr.v15n40p15-26.

26. Oliveira JD, Miranda MLF, Monteiro MDV, Almeida VDF. O brincar e a criança hospitalizada: visão de enfermeiras. Rev Baiana Enferm. 2016;30(4):1-8. http://dx.doi.org/10.18471/rbe.v30i4.16414.

27. Ullan AM, Belver MH. Play as a source of psychological well-being for hospitalized children: study review. Int Ped Chi Care. 2019;2(1):92-8. http://dx.doi.org/10.18314/ipcc.v2i1.1613. 